\title{
EUNOMICS AND ADMINISTRATIVE PROCESS
}

\author{
JOSEPH LAZAR*
}

$\mathrm{E}$ UNOMICS, the science, theory, or study of good order and workable arrangements, ${ }^{1}$ attempts to fuse the traditional values and methods of law with the social and behavioral sciences. The processes of administrative tribunals are reflected in and are shaped by the adjective law of the tribunals. The vital connection between legal procedure and dynamic administrative process may be seen more clearly through the jurisprudential glasses and framework of eunomics. This article will focus on the procedures and processes of the National Railroad Adjustment Board, First Division.

The National Railroad Adjustment Board, First Division

The Board was created by Congress in 1934 to provide for prompt and orderly settlement of "disputes between an employee or group of employees and a carrier or carriers growing out of grievances or out of the interpretation or application of agreements concerning rates of pay, rules, or working conditions . . . ."2 The First Division of the Board has jurisdiction over disputes involving train and yard service employees of carriers. ${ }^{3}$ The membership of

*A.B. 1938, J.D. 1940, University of Chicago. Member, Illinois and Michigan bars. Author or coauthor of DUE Process on tHE RAILROAdS (rev. ed. 1958), RECENT Gases and Materials in Business law (1955), Industrial Relations and the Govern. MENT (1954), READINGS AND MATERIALS IN BUSINESS LAW (1951); contributor to legal periodicals. Law and Behavioral Science Senior Research Fellow, University of Chicago Law School, 1957-1958.

${ }^{1}$ The term "eunomics" was coined by Professor Lon L. Fuller. See Fuller, Ameri. can Legal Philosophy at Mid-Century, 6 J. LEgal ED. 457 (1954). See also Lazar, A Note on Tension Reduction in the National Railroad Adjustment Board System, 7 Behaviorar Science 474 (1962); Lazar, Eunomics and Justice, 1963 DUKe L.J. 269; Lazar, Eunomics: A Behavioral-Science View of the National Railroad Adjustment Board System, 1961 Duke L.J. 262.

${ }^{2}$ Railroad Labor Act $\S 3$ First (i), 48 Stat. 1191 (1934), 45 U.S.C. § 153 First (i) (1958).

${ }^{3}$ The Board is composed of four divisions whose proceedings are independent of one another. Eighteen of its thirty-six members are selected by the carriers and eighteen are selected by unions which are national in scope. Each member of the Board is compensated by the party or parties he is to represent. The Brotherhood of Railroad Trainmen, the Order of Railway Conductors and Brakemen, the Brotherhood of Locomotive Engineers, the Brotherhood of Locomotive Firemen and Engine- 
the First Division is composed of five carrier representatives and five representatives of labor organizations which are national in scope. Decision is by majority vote. Should the bipartisan board deadlock, provision is made for appointment of a neutral referee."

Conceptually, the Board may be viewed as a behavioral system and as possessing the properties of a behavioral system. In brief, a behavioral system (1) exists in space-time, (2) has calculable boundaries, (3) is made up of parts or subsystems, (4) has energy interchange, inputs and outputs, crossing the boundaries between the system and its environment, (5) has energy interchange among its parts or subsystems, and (6) tends to maintain a state of equilibrium both internally among its subsystems and externally with its environment.

The Board, viewed as a behavioral system, exists in space-time; it has boundaries separating it from carriers, unions, courts, and other institutions; it is made up of its carrier and union parts or subsystems; it has input grievances and output awards crossing the boundaries between itself and the railroad and external environments; it has interaction or energy interchange between its parts or subsystems in the disposition of grievances and other matters; and it copes with internal and external stresses and tensions as it strives to maintain internal equilibrium and external balance in processing the input grievances into output awards. ${ }^{6}$

men, and the Switchmen's Union of North America each have one representative member on the First Division. (1958).

\&ailway Labor Act $\S 3$ First (m), 48 Stat. 1191 (1934), 45 U.S.C. § I53 First (m)

- Useful references on behavioral systems theory include Herbst, $A$ Theory of Simple Behavioral Systems $I, 14$ Human ReIs. 71 (1961); Herbst, Situation Dynamics and the Theory of Behavior Systems, 2 BeHavioral, ScIENCE 13 (1957); Miller, Toward a General Theory for the Behavioral Sciences, 10 AM. Psxchologist 513 (1955); von Bertalanffy, Theoretical Models in Biology and Psychology, $20 \mathrm{~J}$. Personality 24 (1951); von Bertalanffy, The Theory of Open Systems in Physics and Biology, 111 Sarance 23 (1950).

- The analogy is amplified in Lazar, Eunomics: A Behavioral-Science Diew of the National Railroad Adjustment Board System, 1961 DukE L.J. 262. Other literature on the Board includes KaLtenborn, Governmental ADJustment of LABOR Disputes 37-72 (1943); Kaufman, Collective Bargaining In the RaIlroad Industry (1954); LAzAR, Due Process on the RaIlroads (rev. ed. 1958); McNaughton \& Lazar, Industrial. Relattons aNd the GovernMent 95-138 (1954); SPENCER, The National Railroad Adjustment BoARd (8 U. Chicago Studies in Bus. Adm. No. 3, 1938); Lazar, Eunomics and Justice, 1963 Duke L.J. 269; Lazar, Tension Reduction in the National Railroad Adjustment Board System, 7 Befavioral ScIENce 474 (1962); Lazar, The Human Sciences and Legal Institutional Development: Role and Reference Group Concepts Related to the Development of the National Railroad Adjustment Board, 31 NoTRE DAME LAw. 414 (1956); Northrup \& Kahn, Railroad Grievance Machinery: A Critical Analysis, 
II

INTERNAL EQUILIBRATION OR HOMEOSTASIS

A. Jurisdiction: Subject Matter and Input Screening

Mechanisms of equilibration exist within the system of the Board. ${ }^{7}$ The intake of grievance disputes generates stresses which impose varying degrees of strain on the system in transforming the inputs into outputs. Certain stresses are more serious than others, since they produce strains beyond the system's range of correction and thus threaten the system with collapse. The system therefore filters or screens out indigestible inputs, and this filtering is essential to the system's effective functioning. In legalistic terminology, the Board's jurisdictional requirements may be seen as such a screening process. Disputes in the range of "making" or "changing" collective bargaining agreements are normally excluded from the Board's intake, as outside its jurisdiction, while disputes involving the range of "interpretation" or "application" of collective bargaining agreements are admitted into the system. "Major" collective bargaining disputes are barred from admission, while "minor" grievances are allowed. The range between the admissible and the inadmissible is wide and uncertain, although the cases at the extremes are clear and distinct; as a result, cases of varying stress, some producing severe degrees of strain, cross over into the system of the Board.

The screening of inputs into the Board system involves not only the subject matter of the disputes but also the enforcement of time limitation concepts, such as laches and statutory or collective bargaining time limitations, which kill off potential inputs of unknown quantity and stress. Peculiar difficulties of proof, extremely large monetary claims, and bargaining pressure tactics are some of the stresses barred from entry by application of time limitation rules.

An especially helpful screening function is performed by the doctrine that awards are final, the notion of res adjudicata. Once the Board system has undergone the strain of transforming an input grievance into an output award, the strain is terminated and internal

5 Ind. \& LaB. Rel. REv. 365 (1952); Comment, 18 U. CHI. L.R. 303 (1951); Note, 51 YALE L.J. 666 (1942).

7 Alfred E. Emerson develops the idea of dynamic homeostasis in his thought-pro. voking paper entitled Dynamic Homeostasis: A Unifying Principle in Organic, Social, and Ethical Evolution, 78 ScrenTrFic MONTHLY 67 (1954). Emerson attributes the concept of homeostasis to Walter Cannon, and he credits Walter Cannon and Ralph W. Gerard with contributing to the concepts of physiological and social homeostasis. 
equilibrium is restored. The circularity of input-output-input-output-input is broken by the bar of output finality. To a significant degree, however, a failure to accept fully the doctrine of stare decisis impairs the Board's equilibrium.

The screening of inputs, while it safeguards the Board system from certain stresses, necessarily leaves these stresses with the environmental system which produced them. Over the decades, additional systems, such as the National Mediation Board, collective bargaining committees, emergency boards, and arbitration boards have been developed with specialized personnel and resources for transforming the stresses into nonviolent and noncombustible material. Accordingly, the appropriate screening of inputs into the Board system results in a channeling of other stresses to a more efficient system and thereby protects the efficient functioning of the railroad suprasystem. The railroad suprasystem may be viewed as a single system composed of component subsystems, of which the Board system is an interacting part. Of course, faulty exclusion of inputs from the Board system may leave unresolved stress and strain in the environmental railroad system or suprasystem, with resultant damage to all systems concerned. Internal equilibration of the Board system goes hand in hand with the maintenance of a homeostatic balance of the system with its external environment.

\section{B. Jurisdiction: Input Screening of Parties}

Customarily the only grievance dispute inputs into the Board were those submitted by the railroads or the railroad brotherhoods with membership on the Board. The Board would refuse to admit both grievance disputes submitted by individuals as parties and those submitted by rival unions without representation in the membership of the Board. The railroads and the railroad brotherhoods judged the efficacy of Board awards by their reduction of stressful materials giving rise to strain. The accumulation of grievance disputes, in other words, was seen as threatening industrial peace (the containment of strain within the boundaries of the particular railroad system threatened the equilibratory resources of the particular railroad system, and such strain would be absorbed by the Board system), and the settlement on the Board of the disputes by the principal parties concerned, the railroads and the railroad brotherhoods, doused the sparks which threatened to flare into industrial warfare. 
Disputes of individuals and rival unions ordinarily would not contain such elements of stress that they would either produce strain between the railroads and the standard brotherhoods represented on the Board or threaten to destroy the peace or equilibrium between these interacting systems. In recent years, however, the Board has accepted jurisdiction of individual and outside union grievances. As might be anticipated, since such disputes contained little stress and produced slight strain on the relations between the railroads and the represented brotherhoods, the disputes on the whole have been denied in perfunctory fashion. ${ }^{8}$ Denial awards, properly worded, imposed no financial or operating stress on the railroads, and denial awards weakened opposition to the brotherhoods.

The membership composition of the Board into the subsystems of management, union, and referee is functionally adapted to the elimination or reduction of stressful materials whose accumulation heightens the probability of industrial conflagration. The Board system undergoes slight strain in disposing of grievance disputes involving individuals or outside unions, since negative awards usually are in the direction of equilibrium and homeostasis for both the management and union subsystems of the Board. Such cases may be said to be determined by hostile, prejudiced judges. It is not unlikely that continued strain for individual and outside unions resulting from negative awards will produce efforts towards strain reduction or equilibrium by appeal to the judicial system; and the courts, confronted with such materials of stress, will be under strain in seeking to link up their decisions in such cases with judicial precedent in the category of due process of law. As a consequence, judicial output in such cases would be brought by individuals and outside unions into the Board system and would constitute an input of stressful material inducing further strain in the Board system. Should this process continue over time, it may be anticipated that Board output and court output would be linked equally with the category of due process of law and that equilibrium would be achieved. Whether such a process of correction is possible in the Board system without either causing the system to collapse or requiring a modification of the structure of the system is a matter of conjecture.

${ }^{8}$ See Lazar, Eunomics and Justice, 1963 DukE L.J. 269; Lazar, Tension Reduction in the National Railroad Adjustment Board System, 7 BEHAvioral Scrence 474 (1962). 


\section{Procedures for Parties}

The transformation of an input grievance dispute into an output award is essentially a process of information transmission. Rules of procedure applicable to the parties to the dispute and internal procedures of the Board's interacting subsystem components constitute the process of information transmission. Efficient transmission harmonizes the two sets of procedures. If all necessary information is included in the input submission, then further informational additions in the form of pleadings and evidentiary hearings are unnecessary; and the internal procedures of the Board system can supply decisional information to the parties, thereby eliminating the grievance stress and reducing the strain between the parties. In brief, then, procedural rules are most effective when initial input comes to the Board with all the essential information, and internal procedures are most effective when there is the least cost in energy in supplying decisional information to the parties.

The procedural rules of the Board are adapted to producing inputs containing all necessary information. Thus, the parties are required to give each other notice of the submission of the dispute to the Board and to file with the Board written submissions containing the statement of claim, a statement of facts (jointly if possible), and a statement of position. The submission must include all the data relevant to the dispute. The parties are invited to waive any hearing. Since the submission must include all relevant data, additional evidence is not admitted at hearings; and the hearings are purely pro forma or perfunctory, without witnesses, without stenographic record, and with only a reading of the written submissions. The holding of hearings of this nature does not appear to further the process of information transmission. Questions of notice ordinarily would not arise between a particular railroad and a standard railroad brotherhood, since the dispute between them already would have been handled in due course on the railroad property as a necessary condition for the Board's jurisdiction.

Judicial recognition of individual and outside union rights, however, seemingly requires that such parties have the right to supply information to the Board relevant to the grievance dispute, and thus, for such parties, the procedural rules of the Board call for some supplementation as to notice and the method of submitting information. These parties have asserted that they should have the right to 
transmit relevant information at hearings rather than being required to submit their dispute to the Board solely in writing, and they have contended further that they should have the additional right to transmit information directly to the referee at hearings to be held before him. On occasion, certain railroad managements and the management subsystem of the Board have also contended that additional hearings should be held before referees. The union subsystem of the Board, however, has opposed such additional informational input procedures. Such procedures, they allege, would result inevitably in time consuming delays when the Board already has difficulties due to a large backlog of undecided dockets. The union subsystem has voiced the view that the procedural rule changes desired by the management subsystem have as their ultimate purpose the destruction of the Board system and the creation of substitute special or regional railroad adjustment boards. Whether procedural changes resulting in time delays in the input-output functioning of the Board system actually would result in an excessive docket backlog, which would represent indigestible inputs to the Board and insufficient outputs to the railroad environmental railroad system, thereby destroying the interual equilibrium and external balance with the system's environment, is problematic. However, this is not an unlikely consequence. It may be noted in this connection that a slower rate of output by the Board in recent years has been accompanied by an increase in special railroad adjustment boards.

\section{Internal Board Procedures}

The transformation of an input grievance dispute into an output award calls for the addition of decisional information to the input information transmitted by the parties. This is work which proceeds according to the internal procedures of the Board system and component subsystems. These internal procedures appear to be, in essence, a linking or coding process, and internal equilibrium follows upon the making of a successful coupling between questionable grievance behavior information and appropriate standard of behavior information. The internal exchanges within the system and subsystem may be said to function so as (1) to clarify and make commonly understood possible gaps or ambiguities in the grievance behavior information, (2) to clarify and make commonly understood possible gaps or ambiguities in the appropriate standard of 
behavior information, and (3) to couple or code the two kinds of information.

\section{Grievance Event Information}

Ordinarily the grievance behavior information is sufficiently concrete to enable mutual understanding of the specific factual events which gave rise to the grievance. The railroad management subsystem member who is appointed to the Board from the railroad region including the particular railroad involved in the dispute ordinarily will discuss the case with his associates and through feedback will learn whether and to what extent his perception of the grievance events is sufficient. Similarly, the labor subsystem member representing the complaining labor organization may have opportunity to benefit from feedback in conference with his labor associates. The internal procedures of the Board system and of the subsystems are not, it seems, clearly adapted to insure conference, discussion, feedback, and clarity of perception by the entire Board of the behavioral events in the grievance prior to the formal calling up of the grievance docket in the executive session of the Board. Consequently, the Board's executive session becomes the meeting point for attempts at informational interchange with possibilities of reaching a common perception of the grievance events.

In cases involving statements of fact to which the parties have jointly agreed, it is fairly simple for Board members to achieve common perceptions. In cases involving disciplinary problems, however, the written submission usually contains a stenographic record of a hearing conducted on the railroad property, and this record may contain contradictory or inconsistent versions by witnesses of the relevant facts giving rise to the grievance. As a result, there is often sufficient ambiguity or indefiniteness about the grievance events to permit the management and labor members of the Board to reach differing perceptions in the direction of least strain, i.e., to perceive the relatively ambiguous events in a manner that will support the position of the parties they represent. The tendency is to see the favorable side of one's own story, while the favorable side of the opponent's story is not so clearly seen.

In cases involving great strain, with possible repercussions on the tenure or security of the Board members, even slight ambiguity or unstructuredness in the grievance events may give rise to differing 
perceptions of the grievance events. It is not until the referee subsystem comes into play, if the case is deadlocked, that a relatively neutral and objective perception of the grievance events may be had; but even at this stage of the proceedings, there are often peculiarly technical and specialized railroad matters requiring perception which in the nature of things the nonrailroad referee is unqualified to see. As a consequence of all this, there are at times misconceptions of the grievance events, and such misconceptions result in inappropriate coding and decisional information output by the Board system. Additional procedures of reality orientation, such as more effective hearing or investigation procedures, a refusal to accept jurisdiction of such ambiguous informational input grievances, a greater willinguess to dismiss such cases without supplying decisional information, or structural and compositional modifications in the Board system might produce a more realistic perception of the grievance events and more appropriate awards.

\section{Standard of Behavior Information}

The input of grievance disputes into the Board system constitutes stress and produces strain until equilibrium is restored with the output award. Ordinarily, there is greater strain within the system in arriving at appropriate standard of behavior information than there is in arriving at a common view of the grievance behavior information. Grievance behavior information normally is concretely structured by the parties with little leeway for distortion or invention by the Board, but appropriate standard of behavior information may be found or shaped by the Board from any number of sources. These sources include ( 1 ) the collective bargaining contracts on the particular railroads; (2) the usages and conventions and negotiated settlements on the particular railroads; (3) the many decisions of early adjustment boards, arbitration boards, or similar railroad industry mechanisms; (4) railroad customs and practices generally prevalent throughout the industry; (5) past decisions of the Board; (6) statutory material such as the Railway Labor Act; (7) the common law; (8) collective bargaining practices and standards in other industries; (9) the religious, moral, and ethical codes of the community; and (10) the disciplines of economics, management, and political science. The creative human spirit, with its mysterious 
workings of mind and intelligence, may shape behavioral standards in words from innumerable sources and components.

Perceived discrepancy between actual behavior and standards of behavior ordinarily produces strain in human systems, and perceived congruence restores equilibrium. Congruence in one system, however, may be destroyed if a conflicting standard of behavior of some other system is perceived as applicable. Thus, if behavioral standards from outside the system are perceived to apply and such standards are not complied with, the incongruency produces strain, and the system's equilibratory resources or homeostatic processes are called upon to produce a new equilibrium. The achievement of equilibrium largely depends, then, on declaring the new standard as governing behavior within the system to which future behavior must conform. The linkage of similarly perceived behavioral events to similarly perceived behavioral standard information may be said to result in equilibrium within a single system. Where more than a single system is involved, however, as where suprasystem, system, and subsystem components comprise bounded regions in space-time and informational interchange across boundaries takes place, strain will continue until what may be called strict equality of exchange is attained, that is, until all systems involved, from the largest to the smallest, hold similar perceptions of grievance event information linked to similar perceptions of grievance standard information. Identical coding, strict equality of interchange of information, and congruence are related to equilibrium, balance, stability, or order and imply absence or reduction of strain, tension, conflict, or dispute. Accordingly, inputs of standard of behavior information or inputs of grievance behavior information or both tend to modify the tension state of the intaking system, and strain, conflict, or dispute continue until successful coding or linkage has occurred.

It may be noted that there is great complexity in the hierarchy of systems whose coding behavior must be equilibrated in the interchange of information in the railroad suprasystem, and the Board system's function is peculiarly interrelated with its environment. To begin with, a grievance dispute ordinarily results from an individual railroad employee's perception of particular railroad events which is incongruent with his behavioral standard information. In such cases, it is often true that the behavioral events and the behavioral standards are correctly linked. For example, the collective bargaining 
agreement is correctly interpreted and applied by management, but the subsystem strains within the individual produced by such factors as financial needs distort perceptual intake of the actual railroad events or have produced distortion of the standard of behavior information previously brought into the individual's system. Feedback mechanisms, such as refiective thinking or discussion with other employees, the union representative, or the local supervisor, may lead the individual to correct his distortions, and his grievance then may be terminated.

At times, the individual employee's perceptions are valid, but the individual supervisor's perceptions may be distorted because the supervisor's own subsystem components are in a state of tension, growing out of status needs, for example. Grievance communications with the aggrieved employee, his representative, or higher management may correct his distortions, and the grievance will then be settled. Where the supervisor's perceptions continue to be held, the local union representative may interchange information on the grievance with the individual employee; the resulting temporary subsystem of individual employee and local union representative may have its own equilibrium needs (such as personal friendship or animosity, union membership or union rivalry, etc.) which may be satisfied by further handling or output of the grievance or by a refusal by the local union representative to process the grievance.

Subsequent upward transmission of the grievance information, both on the part of management and union, generally results in informational exchange about the grievance events. Here, it is significant that the exchange is now between parties who have had no perceptual inputs of their own concerning the grievance event. At the highest echelons of management and union, however, although there is no direct perception of the grievance events, there is usually a more correct perception of the grievance standard information, for the collective bargaining agreement provisions which apply to the grievance may have been negotiated or become mutually understood by top management and top union personnel through years of experience in applying them. In the subsystem of top railroad and union management, therefore, perceptual distortion at the grievance event level is likely to be greater than perceptual distortion of the grievance standard information; and at the lower levels, there is more likely to be a distortion of the grievance standard in- 
formation. Where the grievance standard information is unclear due to gaps in the collective bargaining agreement or there is an ambiguity, it becomes more difficult to link or code the two kinds of information, and the resultant strain on the system may eject the stressful material into the Board system.

Standards of behavior range from those which are broad and almost universal in scope to those which are narrow and particularistic. Thus, it is more likely for strain to occur in coding standard of behavior information calling for a fair hearing in disciplinary grievances than it is for strain to occur in coding standard of behavior information calling for the use of the first man out on the extra board. On the particular railroad property, subsystems of management and labor may be unable to apply the same behavioral standard information to the requirement for a fair hearing; and the unsuccessful linkage attempt will result in the grievance dispute being sent out from the railroad system and becoming an input of the Board system.

It should be noted that, on the whole, the standard of behavior information set forth in the collective bargaining agreements on the railroad systems of the nation is forty or more years old. Even though they were negotiated to deal with relatively primitive railroading conditions, the collective bargaining agreements have not been rewritten to keep pace with technological change. Faster trains with more efficient motor power, improved and heavier track, modern car retarder train classification yards, and centralized traffic control have modified the time and labor required by railroad workers; however, the collective bargaining agreements perpetuate earlier restrictions on managerial use or abuse of manpower and impose certain uneconomic costs for manpower under modern standards.

Modification of the collective bargaining agreements through negotiation is a slow and difficult process. While this continues, there is no practical alternative to applying the existing collective bargaining agreement provisions to modern railroad technology. It is to be expected, therefore, that the coding of information involving the modern railroad technology to the antiquated collective bargaining provisions produces strain. Managerial subsystem efforts to benefit economically from the technological innovations lead to a modified and sharper look at the old collective bargaining provi- 
sion. The new perception may be in conflict with the older customary linkage or application of the working rules; and the earlier linkage, by supplying more favorable economic inputs into the work. er subsystem, tends to be perceived by the union subsystem as congruent with changed conditions. Possibilities of strain are produced when the managerial subsystem attempts unilaterally to code the old working rules to the changed technology, and resultant strains are evidenced in part by the grievance dispute informational flow across the boundaries of particular railroad systems to the Board system.

\section{Coding and Precedent}

Perceived congruence between an input grievance and previous output awards of the Board ordinarily leads to a coding of the grievance with such prior awards, which are called precedents. Although strains are reduced with the issuance of awards, there are instances when seemingly inconsistent awards are made, and the incongruence perceived in the awards continues the strain in the Board system. Consistency in awards tends to reduce strain, and inconsistency in the awards tends to heighten the level of strain. The inconsistent awards constitute conflicting standard of behavior information, and they remain a source of tension both within the Board system and the environmental railroad systems. On the other hand, consistent coding by the Board system over time leads to consistent coding within the environmental railroad systems, and overall equilibrium in the suprasystem is thereby attained.

It is noteworthy, however, that the management and union subsystems of the Board at times perceive congruence between output awards, although they persist in perceiving incongruence between what they regard as appropriate standards of behavior and the standard of behavior information applied in the decided cases. Thus, in the railroad yard category of disputes, the management subsystem is highly conscious of the monotonous and repetitive consistency of awards sustaining roadmen's claims for additional compensation at yardmen's rates for performing yard service; nevertheless, the management subsystem does not perceive the decided awards as appropriate standard of behavior information in view of clearly expressed, unambiguous, plainly worded contractual provisions which stipulate rates and amounts of pay to roadmen for exactly the yard services 
performed. In such cases, financial and operating strains upon the environmental railroad management subsystems, apart from incongruence between the decided cases and rules of standard of information interpretation which are usually followed, make the awards difficult to digest; consequently, tension continues. This kind of suprasystem tension, it should be emphasized, constitutes a strain destructive of the equilibratory resources of the Board system. Such strain operates to prevent the coding of one Board award to another. In such situations, where awards ordinarily would issue based upon precedent, deadlock instead ensues. The referee subsystem, therefore, must make the coding determinations. Referees, because of their inexperience in practical railroad technology, tend to distort grievance event information as well as behavioral standard information which ordinarily would be available within the railroad suprasystem for coding purposes.

Because of many differences in educational background, profession, experience, and intelligence among referees, there is difficulty in attaining consistency in the output awards of the Board. The inconsistency makes it more difficult for particular railroad systems to code successfully behavioral standard information with grievance event information. The ensuing strains tend to result in additional grievance inputs into the entire railroad suprasystem. As noted before, the additional strains on particular railroad systems are eased through the creation of special adjustment board systems. This form of system building does not promise any eventual solution to the tensions within the suprasystem. It would seem that these tensions can only mount in the absence of an effective coding mechanism able to consistently apply behavioral standard information to grievance events.

Conceivably, the referee subsystem should be able to bring about a successful coding of one Board award to another and particular railroad behavioral standard information to Board awards, and thus establish in the long run a condition of equilibrium in the railroad suprasystem. The difficulty in attaining equilibrium seems to lie in (l) distortion by the referee in perceiving (a) grievance events, (b) behavioral standard information submitted by the parties-the collective bargaining agreement's technical working rules jargon, and (c) previous Board awards; and (2) a search by the referee for additional standard of behavior information drawn from environ- 
ments in the social system external to the railroad suprasystem. The referee attempts to find additional information which, when added to the behavioral standard information present in the Board system, will reduce strain within the union, management, or both subsystems and will restore Board system equilibrium. Thus, the referee brings new informational inputs into the Board system, and such inputs become merged in the award outputs of the Board system and produce strain in the entire railroad suprasystem. For example, the referee with a legal or judicial background introduces the rules of legal interpretation of contracts as additional information in determining behavioral standard information. Rules of legal interpretation are usually followed more expertly by lawyers than by laymen. Consequently, the railroad management systems employ attorneys to assist its laymen, or to substitute for its laymen, in the administration of the collective bargaining agreements and in the preparation of the management submission of the grievance dispute to the Board. This innovation of legal personnel by management brings in its wake legalistic interpretations of the collective bargaining agreements which are biased by management and individual subsystem strains. These legal standards are no longer consistent with the previously administered layman grievance behavior standards. Serious disturbances of equilibrium between the management and union subsystems on particular railroad systems result. Additionally, attorneys are used in the management subsystem on the Board. Management subsystem tensions result from difficulty between legal and lay members in reaching a common perception of applicable behavioral standard information and additional information, such as rules of interpretation and common railroading practices, which are useful in reaching behavioral standard information appropriate for strain reduction in output award making.

In addition to introducing rules of interpretation of contracts, the referee brings in information which attempts to rationalize past awards cited to him by the management and union subsystems. The discussion or informational exchange with the regular members leads the referee to verbalize reasons for past decisions although such reasons were not supplied in the past decisions themselves. Thus, similarities in awards are noted, dissimilarities become verbalized, the reason for the decision is stated, and the rule of stare decisis acquires breadth and depth. This is a highly significant kind of 
input by the referee. Such input of information constitutes, in effect, a legal principle of substantive weight. It is a kind of standard of behavior information which may be different from the behavioral standard information contained in the collective bargaining provisions and customs and practices in the railroad suprasystem.

As a consequence of this verbalization or formulation of the governing substantive legal rule or principle, tensions arise not only in the Board system but also in the particular railroad systems as to coding correctness. Should the grievance event information in a particular case be coded (1) to the unequivocal collective bargaining agreement provision (as in the scores of railroad yard cases first reaching the Board), (2) to output awards of the Board system which do not express reasons for decision, or (3) to the more recent output awards of the Board system which state the underlying reason or principle of decision? Since the Board's output awards are published and circulated through the communication networks of management and union subsystems in the environmental railroad system, the input information of principles of decision by referees disturbs the equilibrium in the railroad suprasystem. Input and output needs of individuals, small groups, and larger component subsystems of the railroad suprasystem lead to perception of new incongruities in the coding of grievance event information to behavorial standard information. The equilibratory resources of the railroad suprasystem and its component subsystems must cope with the new strains of coding brought about by the introduction of the new standard of behavior information contained in referee awards.

Board system and railroad suprasystem strains resulting from stressful informational inputs by referees are to be anticipated and should be regarded as inherent in the operation of the referee subsystem. The role of referee has been filled by individuals with different personality characteristics as well as dissimilar educational and occupational backgrounds. Thus, individuals coming to the referee role from judicial employment are, in a sense, transmitters of information from their judicial system to the Board system. Lawyers serving as referees transmit information from the legal systems of their experience. This is likewise the case with referees drawn from industrial relations, consultant, arbitral, economist, or professorial categories and systems of vocational and professional experience. 
The referee role is, in a sense, a role linking the Board system to nonrailroad environmental systems in the social system. Thus, the referee may be seen as a transmission channel which penetrates the boundaries of the Board system. His inputs affect the equilibrium of the Board system, its balance with the railroad suprasystem, and the balance of the railroad suprasystem with other social systems. It may be anticipated that the referee's inputs may result in varying degrees of strain on the Board system (1) where the referee may introduce inputs affecting the jurisdiction of the Board, (2) where the referee may introduce information relating to the procedures to be followed by parties to grievances, or (3) where the referee may introduce information relating to the procedures to be followed by the Board system or subsystems in their internal procedures. Such referee inputs constitute standard of behavior information to which the Board members must code their own present and future behavioral activities, and they occasionally produce such strain that the equilibratory resources of the system are threatened.

\section{III}

\section{ConcLusion}

Eunomics offers a conceptual framework or form into which the content of traditional legal concepts can be analyzed and reorganized. Thus, as seen in the example of the National Railroad Adjustment Board, the concept of jurisdiction over subject matter is brought into the framework of equilibration or homeostasis, and such legal concepts as laches, statutory limitation, res adjudicata, and stare decisis are also brought within the same form. The form of equilibration or homeostasis is also useful in contributing insight toward the appropriate functioning of sister collective bargaining mechanisms under the Railway Labor Act, such as the National Mediation Board, arbitration tribunals, and presidential fact finding boards.

The concept of jurisdiction over the parties is seen as fitting into the form of balance between the Board and its environment. This jurisdictional concept is also seen as related to the membership composition of the Board, and in its balance form it is further related to concepts of due process of law and the judicial system.

Procedural rules which the Board applies to both parties and 
itself are cast in the forms of information transmission and processing. Thus, the requirements of notice, submissions by parties, hearings, and appeals are related to internal board procedures, and both processes are placed in the forms of internal equilibration and external balance. The legally operative facts of cases are placed in the category of grievance event information, and the legally operative rules which govern conduct are placed in the category of grievance standard information. The stage of decision making or administrative adjudication is seen as coding the two forms of information. Further, the concept of precedent is seen within the framework of coding and within the framework of equilibration, both internally within the Board and externally with the environmental social system. The role and function of the referee as adjudicator is seen in the larger social framework.

In conclusion, eunomics may be understood as supplying new forms and frames of reference for understanding traditional legal concepts and processes. The insights suggested through the use of the powerful glasses of eunomics may indicate ways and means of coping administratively with social problems and achieving administrative justice. 